\title{
Changes in tobacco use among 13-15-year-olds between 1999 and 2007: findings from the Eastern Mediterranean Region
}

F. El-Awa, ${ }^{1}$ C.W. Warren ${ }^{2}$ and N.R. Jones ${ }^{2}$

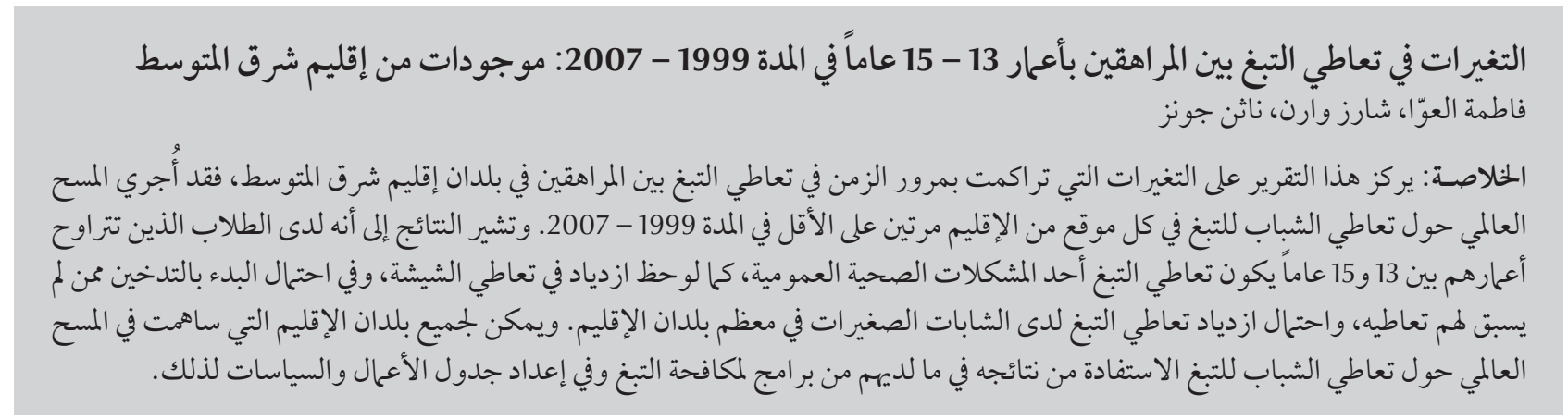

ABSTRACT This report focuses on change over time in tobacco use among adolescents in countries included in the Eastern Mediterranean Region (EMR) of the World Health Organization. The Global Youth Tobacco Survey (GYTS) was conducted in each site at least twice between 1999 and 2007. Results indicate that for students aged 13-15 years tobacco use is a major public health problem. Increase in the use of water pipe, the likely initiation of smoking by never smokers, and a potential increase in tobacco use among young girls was found in most of the EMR sites. The results from the GYTS can be used by all of the EMR countries involved to set their tobacco control programme and policy agenda.

Changement au niveau de la consommation de tabac chez les 13-15 ans entre 1999 et 2007 : constatations pour la Région de la Méditerranée orientale

RÉSUMÉ Le présent article concerne les changements survenus durant une certaine période au niveau de la consommation de tabac chez les adolescents dans des pays de la Région OMS de la Méditerranée orientale. L'enquête mondiale sur le tabagisme chez les jeunes a été conduite au moins deux fois sur chaque site entre 1999 et 2007. Les résultats montrent que pour les adolescents âgés de 13 à 15 ans, le tabagisme constitue un problème de santé publique majeur. Une augmentation de l'utilisation des pipes à eau, l'initiation probable au tabagisme de personnes n'ayantt jamais fumé, et une hausse potentielle du tabagisme chez les jeunes filles ont été observées sur la plupart des sites de la Région de la Méditerranée orientale. Les résultats de cette enquête peuvent être utilisés par l'ensemble des pays de la Région concernés afin de mettre en place un programme de lutte antitabac et d'orienter leurs politiques en la matière.

'Tobacco Free Initiative, Division of Health Promotion and Protection, World Health Organization Regional Office for the Eastern Mediterranean, Cairo, Egypt.

${ }^{2}$ Office on Smoking and Health, Centers for Disease Control and Prevention, Atlanta, Georgia, United States of America (Correspondence to C.W. Warren:wcw1@cdc.gov).

Received: 12/11/07; accepted: 07/02/08 


\section{Introduction}

Tobacco use is one of the major preventable causes of premature death and disease in the world. A disproportionate share of the global tobacco burden falls on developing countries where $84 \%$ of the 1.3 billion current smokers live [1]. The Global Youth Tobacco Survey (GYTS), part of the Global Tobacco Surveillance System (GTSS) initiated by the World Health Organization (WHO) and the Centers for Disease Control and Prevention (CDC) in 1999, was developed to monitor youth tobacco use, attitudes and exposure to tobacco smoke, and has been completed by over 2 million students in 151 countries [2]. A key goal of GTSS is for countries to repeat the GYTS every 4 years.

Our report presents findings from GYTS conducted more than one time in 13 countries and the areas administered by the Palestinian Authority in the Gaza Strip and West Bank in WHO's Eastern Mediterranean Region (EMR) between 1999 and 2007. The report focuses on changes in the proportion of students who currently smoke cigarettes, currently use other tobacco products (such as water pipe, locally known as shisha or nargileh), and never smokers who are susceptible to initiate cigarette smoking in the next year.

\section{Methods}

\section{Sampling}

The GYTS is a school-based survey that collects data from students aged 13-15 years using a standardized methodology for constructing the sample frame, selecting schools and classes, and processing data. Within each country, the scope of the GYTS is defined through consultation between the country GYTS research coordinator, WHO Tobacco Free Initiative (TFI) regional advisers and CDC technicaladvisers.Depending on the data requirements of the country, resources available and safety concerns, the scope of the GYTS can be national or regional or focused on specific urban or rural areas. In addition, many samples are designed to yield information that is representative of country geographical regions, but can be pooled to yield nationally representative estimates.

After the sampling frames are defined, the GYTS research coordinator provides CDC with school enrolment information and the samples are drawn using a standard protocol and software developed by CDC. The GYTS standard sampling methodology uses a 2-stage cluster sample design that produces samples of students in grades associated with students of $13-15$ years of age. Each sampling frame includes all schools (usually public and private) in a geographically defined area containing any of the identified grades. At the first stage, the probability of schools being selected is proportional to the number of students enrolled in the specified grades. At the second sampling stage, classes within the selected schools are randomly selected. All students in the selected classes attending school the day the survey is administered are eligible to participate. Student participation is voluntary and anonymous using a selfadministered questionnaire. The GYTS sample design produces representative, independent, cross-sectional estimates for each sampling frame.

\section{GYTS participants}

This report includes data from 13 EMR countries and the areas administered by the Palestinian Authority. Repeat GYTS surveys were conducted in Egypt (2001 and 2005), Jordan (1999, 2003 and 2007), Kuwait (2001 and 2005), Lebanon (2001 and 2005), Libyan Arab Jamahiriya (2003 and 2007), the Gaza Strip (2000 and 2005), the West Bank (2000 and 2005), Morocco (2001 and 2006), Oman (2002 and 2007), Qatar (2004 and 2007), Somalia-Somaliland (2004 and 2007), Sudan (2001 and 2005), Syrian Arab Republic (2002 and 2007), Tunisia (2001 and 2007) and the United Arab Emirates (UAE) (2002 and 2005). These 13 countries and 2 administrative regions will be referred to throughout the remainder of this report as sites.

\section{Data collection instrument}

The core GYTS instrument includes 54 questions covering 7 categories: tobacco use, knowledge and attitudes regarding tobacco, second-hand smoke exposure, pro- and anti-tobacco media and advertising exposure, desire for cessation, access and availability to obtain tobacco, and having been taught in school about the harmful effects of tobacco use. Research coordinators are encouraged to develop and add questions to the core questionnaire to gather information important to their country or WHO Region. The final country questionnaires are translated into local languages as needed and backtranslated to check for accuracy. GYTS country research coordinators conduct focus groups of students aged 13-15 years to further test the accuracy of the translation and student comprehension of the questions.

\section{Variable definitions}

This report describes changes in several important tobacco indicators between 1999 and 2007, including current cigarette smoking, use of other tobacco products and susceptibility of never smokers to initiate cigarette smoking.

- Current cigarette smokers are defined as students who answered "one or more days" to the question, "During the past 30 days (1 month), on how many days did you smoke cigarettes?"

- Current users of other tobacco products are defined as students who answered "yes" to the question, "During the past 30 days (1 month), have you ever used any form of tobacco products other than cigarettes, e.g. water pipe, chewing tobacco, snuff, dip (dipping tobacco), cigars, cigarillos, little cigars, pipe?" 
- Never smokers who are susceptible to start cigarette smoking in the next year are defined as $100 \%$ minus the percentage of never smokers who answered "definitely not" to the question, "If one ofyour best friends offered you a cigarette, would you smoke it?" and also answered "definitely not" to the question, "At any time in the next 12 months do you think you will smoke a cigarette?"

Susceptibility to cigarette smoking defined in the above-mentioned way has been strongly associated with subsequent experimentation with cigarettes among non-smoking students [3]. In multivariate analyses, the susceptibility to initiate cigarette smoking measure was a stronger predictor of experimentation than the presence of cigarette smokers among family and best friends [3] .

\section{Response rate definitions}

The school response rate is defined as: number of participating schools/ number of selected schools. The student response rate is defined as: number of students who completed the survey/ number of students enrolled in the class. The overall response rate is defined as: school response rate $x$ student response rate.

\section{Data analysis}

A weighting factor is applied to each student record to adjust for non-response (by school, class and student) and variation in the probability of selection at the school and class levels. A final adjustment sums the weights by grade and sex to the population of schoolchildren in the selected grades in each sample site. SUDAAN, a software package for statistical analysis of correlated data, was used to calculate weighted prevalence estimates and standard errors (SE) of the estimates; the 95\% confidence intervals (CI) were calculated from the SEs [4]. In this paper differences in proportions are considered statistically significant at the $P<0.05$ level if the $95 \%$ CIs do not overlap.

\section{Results}

Bank, 2005; Oman, 2002 and 2007;

\section{Response rates}

Sample sizes and response rates for the surveys by country are presented in Table 1.

The school response rates ranged from $90.2 \%$ (Egypt, 2005) to $100.0 \%$ (Egypt, 2001; Jordan, 2003 and 2007; the Gaza Strip, 2000 and 2005; the West Syrian Arab Republic, 2002 and 2007; Tunisia, 2001 and 2007; and UAE, 2002 and 2005 (Table 1). The student response rate ranged from $83.7 \%$ (Syrian Arab Republic, 2007) to over 99\% in Lebanon (2005) and Libyan Arab Jamahiriya (2003). The overall response rate ranged from $77.0 \%$ (Egypt, 2005) to 98.3\% (Syrian Arab Republic, 2002). The number of students who

Table 1 Response rates in the Global Youth Tobacco Surveys (GYTS) in countries in the Eastern Mediterranean Region of the World Health Organization, 1999-2007

\begin{tabular}{|c|c|c|c|c|c|}
\hline Site & $\begin{array}{l}\text { Year survey } \\
\text { completed }\end{array}$ & $\begin{array}{l}\text { School } \\
\text { response } \\
\text { rate }(\%)\end{array}$ & $\begin{array}{l}\text { Student } \\
\text { response } \\
\text { rate }(\%)\end{array}$ & $\begin{array}{c}\text { Overall } \\
\text { response } \\
\text { rate (\%) }\end{array}$ & $\begin{array}{l}\text { Number of } \\
\text { students } \\
\text { who } \\
\text { completed } \\
\text { the GYTS }\end{array}$ \\
\hline \multirow[t]{2}{*}{ Egypt } & 2001 & 100.0 & 96.3 & 96.3 & 3792 \\
\hline & 2005 & 90.2 & 85.4 & 77.0 & 4196 \\
\hline \multirow[t]{3}{*}{ Jordan } & 1999 & 91.0 & 92.2 & 83.9 & 3912 \\
\hline & 2003 & 100.0 & 89.1 & 89.1 & 6313 \\
\hline & 2007 & 100.0 & 91.6 & 91.6 & 2250 \\
\hline \multirow[t]{2}{*}{ Kuwait } & 2001 & 100.0 & 94.8 & 94.8 & 6330 \\
\hline & 2005 & 100.0 & 88.7 & 88.7 & 3935 \\
\hline \multirow[t]{2}{*}{ Lebanon } & 2001 & 98.0 & 98.3 & 96.4 & 4951 \\
\hline & 2005 & 98.0 & 99.2 & 95.2 & 3314 \\
\hline \multirow{2}{*}{$\begin{array}{l}\text { Libyan Arab } \\
\text { Jamahiriya }\end{array}$} & 2003 & 98.0 & 99.0 & 97.0 & 1850 \\
\hline & 2007 & 100.0 & 94.1 & 94.1 & 2028 \\
\hline \multirow[t]{2}{*}{ Gaza Strip } & 2000 & 100.0 & 95.8 & 95.8 & 2906 \\
\hline & 2005 & 100.0 & 94.5 & 94.5 & 2109 \\
\hline \multirow[t]{2}{*}{ West Bank } & 2000 & 98.7 & 94.8 & 93.5 & 8374 \\
\hline & 2005 & 100.0 & 95.6 & 95.6 & 2182 \\
\hline \multirow[t]{2}{*}{ Morocco } & 2001 & 98.0 & 94.8 & 92.9 & 3147 \\
\hline & 2006 & 98.0 & 93.5 & 91.6 & 3186 \\
\hline \multirow[t]{2}{*}{ Oman } & 2002 & 100.0 & 96.9 & 96.9 & 1962 \\
\hline & 2007 & 100.0 & 96.8 & 96.8 & 2297 \\
\hline \multirow[t]{2}{*}{ Qatar } & 2004 & 92.0 & 91.9 & 84.5 & 3240 \\
\hline & 2007 & 96.0 & 90.9 & 87.3 & 1434 \\
\hline \multirow[t]{2}{*}{ Somalia-Somaliland } & 2004 & 88.0 & 94.2 & 82.9 & 1563 \\
\hline & 2007 & 96.0 & 90.2 & 86.6 & 1998 \\
\hline \multirow[t]{2}{*}{ Sudan } & 2001 & 94.0 & 94.2 & 88.5 & 2783 \\
\hline & 2005 & 92.0 & 93.2 & 85.8 & 4277 \\
\hline \multirow[t]{2}{*}{ Syrian Arab Republic } & 2002 & 100.0 & 98.3 & 98.3 & 4531 \\
\hline & 2007 & 100.0 & 83.7 & 83.7 & 2039 \\
\hline \multirow[t]{2}{*}{ Tunisia } & 2001 & 100.0 & 94.1 & 94.1 & 4282 \\
\hline & 2007 & 100.0 & 92.4 & 92.4 & 2155 \\
\hline \multirow{2}{*}{$\begin{array}{l}\text { United Arab } \\
\text { Emirates }\end{array}$} & 2002 & 100.0 & 95.1 & 95.1 & 4178 \\
\hline & 2005 & 100.0 & 93.1 & 93.1 & 16447 \\
\hline
\end{tabular}


participated varied due to the level of stratification included in each sample design. For example, Jordan conducted a single national sample in 1999 , but stratified the country into 3 regions in 2003; Lebanon stratified in urban and rural samples in both 2001 and 2005; and the West Bank was stratified into 3 regions in 2000 but not in 2005 .

\section{Current cigarette smoking}

At the time of the initial surveys, current cigarette smoking was highest in Somalia-Somaliland (18.6\%), Jordan (16.6\%) and the West Bank (14.2\%), and lowest in Morocco (2.6\%), Libyan Arab Jamahiriya (4.1\%) and Egypt (4.2\%) (Table 2). Boys were significantly more likely than girls to smoke cigarettes in every site except Egypt and Somalia-Somaliland, which had no gender differences.

Between the initial survey and the repeat survey, the level of smoking decreased significantly in Jordan and Somalia-Somaliland, increased significantly in the Syrian Arab Republic, but did not change significantly in the other sites. Also, at the time of the repeat surveys, gender differences in smoking behaviour did not change in most of the sites. Boys continued to have significantly higher levels of smoking than girls in Kuwait, Lebanon, Libyan Arab Jamahiriya, the Gaza Strip, the West Bank, Qatar, Sudan, Syrian Arab Republic, Tunisia, and UAE. In Jordan, Morocco and Oman there was a change from boys having significantly higher levels of current smoking at the initial survey to no gender difference at the time of the repeat survey; and in Egypt no gender difference at the initial survey changed to boys having significantly higher rate of smoking than girls at the repeat survey.

\section{Current other tobacco use}

During the initial surveys, current use of other tobacco products was highest in Lebanon (38.6\%) and lowest in Tunisia (7.2\%) and the Gaza Strip (7.8\%)
(Table 2). Boys were significantly more likely than girls to use other tobacco products in every site, except Egypt, Libyan Arab Jamahiriya, Morocco, Qatar, Somalia-Somaliland, Sudan and Syrian Arab Republic, which had no gender difference.

Between the initial surveys and the repeat surveys, the level of use of other tobacco products significantly decreased in Egypt and Jordan, significantly increased in Tunisia and UAE, but did not change significantly in the other sites. Also at the time of the repeat surveys, the lack of statistical difference between boys and girls in use of other tobacco products remained in Libyan Arab Jamahiriya, Morocco, Qatar, Somalia-Somaliland and Sudan, while and boys continued to have significantly higher levels than girls in Kuwait, Lebanon, the West Bank, Tunisia and UAE. However, in Egypt and Syrian Arab Republic the relationship changed from no gender difference to boys having significantly higher levels of use of other tobacco products than girls. In addition, in Jordan, the Gaza Strip and Oman the relationship changed from boys having significantly higher levels of use of other tobacco products than girls to no gender difference.

Current use of other tobacco products was significantly higher than cigarette smoking in Egypt, Lebanon, Morocco, Qatar, Syrian Arab Republic and UAE at both the initial and repeat surveys. Current use of other tobacco products changed from being significantly higher than cigarette smoking to no difference in Kuwait, Libyan Arab Jamahiriya and Sudan. In the Gaza Strip, the West Bank, Somalia-Somaliland and Tunisia, the relationship changed from no difference to the use of other tobacco products being significantly higher than cigarette smoking. In Jordan the relationship changed for cigarette smoking being higher than use of other tobacco products to no difference.

\section{Susceptibility of never smokers to initiate cigarette smoking in the next year}

During the initial surveys, susceptibility to initiate cigarette smoking among never smokers was highest in SomaliaSomaliland (25.0\%), Sudan (22.3\%), Tunisia (19.8\%) and Libyan Arab Jamahiriya (19.5\%) and lowest in the Gaza Strip (6.6\%) (Table 2). Boys were significantly more likely than girls to be susceptible to initiate cigarette smoking in Lebanon, the West Bank, Morocco, Tunisia and UAE; in all other sites, there was no gender difference.

Between the initial surveys and the repeat surveys, susceptibility to initiate cigarettesmokingsignificantly increased in Jordan, the Gaza Strip and the West Bank, significantly decreased in Sudan, but did not change significantly in the other sites. Also at the time of the repeat surveys, the lack of statistical difference between boys and girls in susceptibility to initiate cigarette smoking remained in Jordan, Kuwait, Libyan Arab Jamahiriya, the Gaza Strip, Oman, Qatar, SomaliaSomaliland, Sudan, and Syrian Arab Republic, and boys continued to show significantly higher susceptibility than girls in Tunisia and UAE. However, in Egypt the relationship changed from no gender difference to boys being significantly more susceptible than girls, and in Lebanon and the West Bank the relationship changed from boys being significantly more susceptible than girls to no gender difference.

\section{Discussion}

Results from this study document that tobacco use among students aged 13-15 years is a significant public health problem in EMR. Three major problems have been identified.

First, use of other tobacco products (especially shisha or nargileh) is a major concern in all the sites, especially Lebanon where almost $60 \%$ of the adolescents are current users. At the time of 


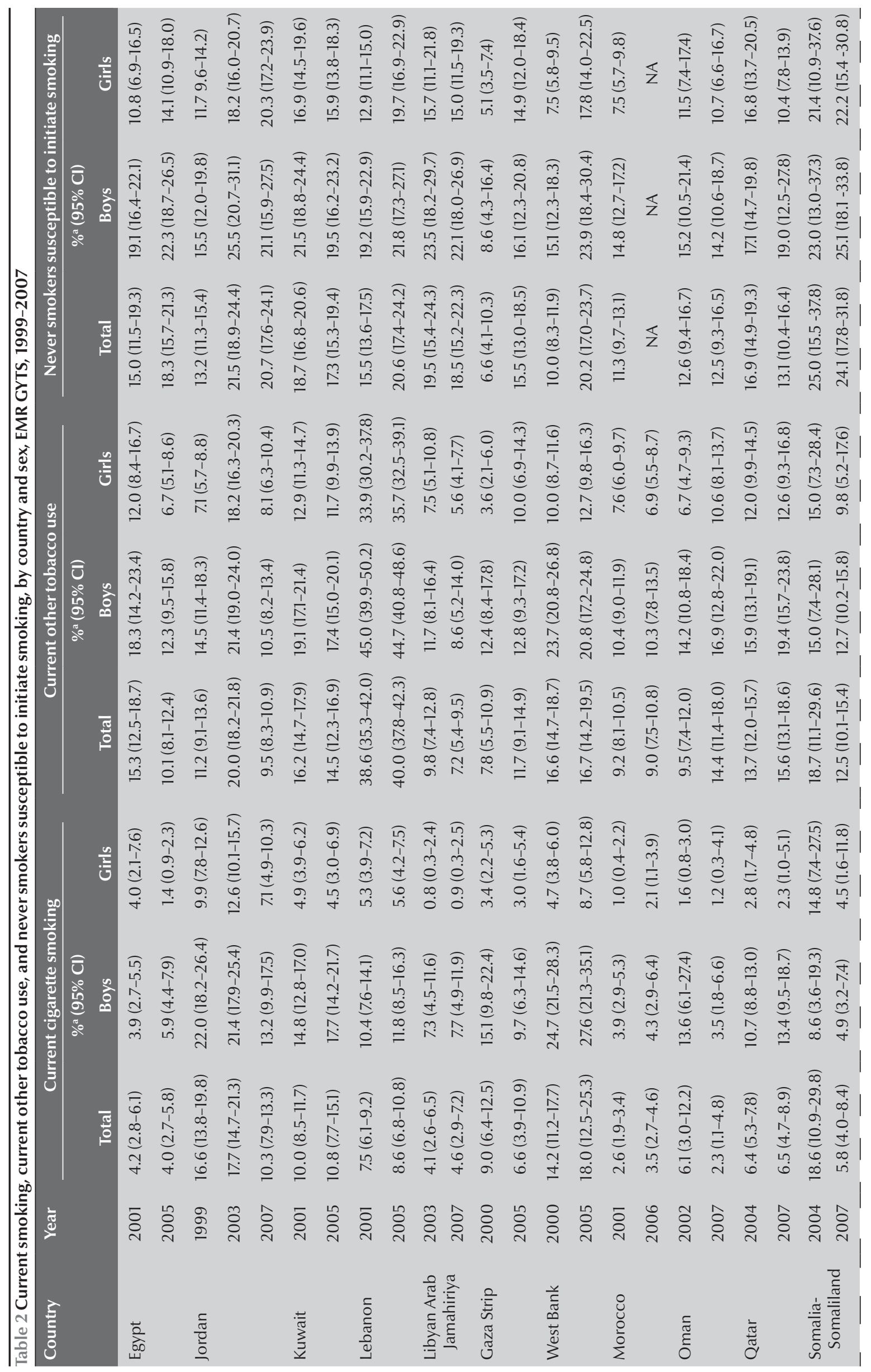




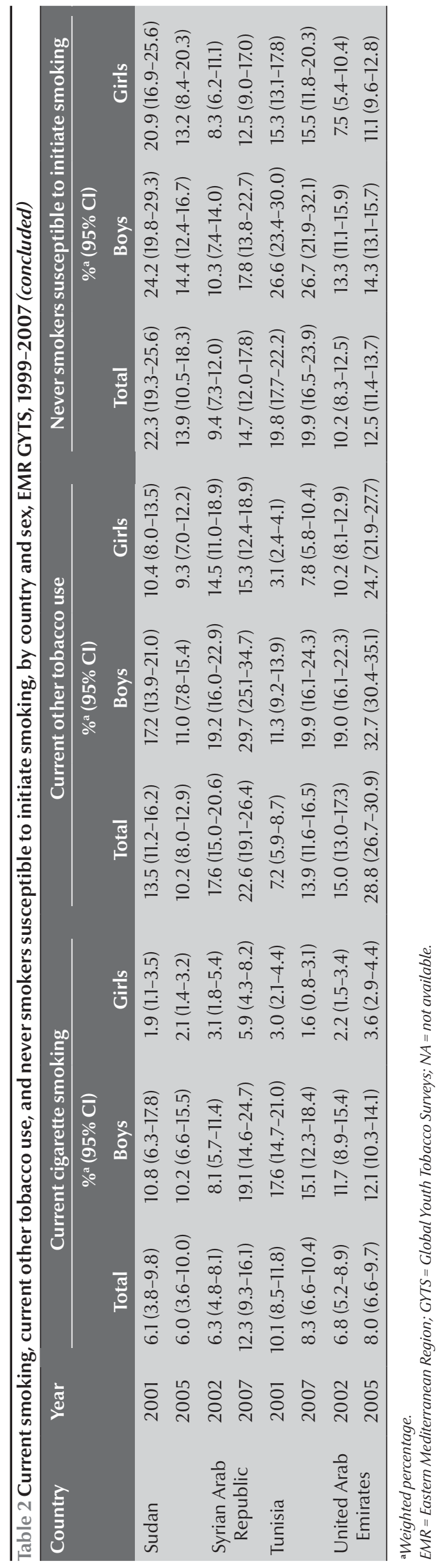

the repeat survey, current use of other tobacco products was significantly higher than cigarette smoking in Egypt, Gaza Strip, West Bank, Lebanon, Morocco, Qatar, Somalia-Somaliland, Syrian Arab Republic, Tunisia and UAE; and there was no difference in Jordan, Kuwait, Libyan Arab Jamahiriya and Sudan. Thus, the tobacco control effort in EMR must include intense efforts directed toward reducing the influence of other tobacco products.

Second, susceptibility to initiate cigarette smoking among never smokers increased significantly in Jordan, Gaza Strip and West Bank; decreased significantly in Sudan; but did not change significantly in the other sites. At the time of the repeat survey, there was no difference in the level of susceptibility for boys and girls, except in Egypt, Tunisia and UAE. These findings suggest cigarette smoking could increase dramatically in these populations in the near future.

Third, tobacco use among young girls appears to be undergoing major changes. The most recent data from the GYTS on the prevalence of smoking among girls is as high, or higher, than the prevalence of smoking among adult women in 9 of the 11 countries where comparisons can be made (Table 3). In addition, the boy:girl ratio is less than the male:female ratio in 10 of the 11 countries. These findings indicate tobacco use among females may be increasing in EMR. Thus, tobacco use among females, especially young girls, should be a priority in the EMR countries.

For decades the tobacco industry has targeted females and continues to expand this market $[5,6]$. The tobacco industry targets women through advertisements showing smoking associated with independence, stylishness, weight control, sophistication and power [7]. The industry markets Virginia Slims, Capri, Misty and Camel No. 9 directly to women using feminine images. In addition, gender-neutral brands such as Marlboro are marketed to women using imagery of independence and "fun-loving". Also, gender norms constantly change. GYTS data showed susceptibility to initiate smoking among never smokers was significantly more prevalent than current cigarette smoking for girls in all sites. This might be an indication that EMR cultural traditions and social influences may be changing thus making smoking among women and young girls more acceptable both at home and in public [8]. These findings suggest the tobacco control programmes in EMR countries should focus on cessation among adult men and on prevention among women and youth (of both sexes).

All of the EMR sites can use the results from the GYTS to inform politicians and policy-makers about the tobacco problems in their populations. The information can be used as baseline data for decision-making concerning National Tobacco Control Action Plans. In addition, Egypt, Jordan, Kuwait, Lebanon, Libyan Arab Jamahiriya, Oman, Qatar, Sudan, Syrian Arab Republic and UAE can use the information as part 


\begin{tabular}{|c|c|c|c|c|c|c|}
\hline \multirow[t]{2}{*}{ Country } & \multicolumn{3}{|c|}{ Adult smoking prevalence } & \multicolumn{3}{|c|}{ Most recent GYTS } \\
\hline & Males (\%) & Females (\%) & $\begin{array}{l}\text { Male:female } \\
\text { ratio }\end{array}$ & Boys (\%) & Girls (\%) & Boy:girl ratio \\
\hline Egypt & 45.4 & 12.1 & $3.8: 1$ & 5.9 & 1.4 & $4.2: 1$ \\
\hline Jordan & 50.5 & 8.3 & $6.1: 1$ & 13.2 & 7.1 & 1.9:1 \\
\hline Kuwait & 34.4 & 1.9 & 18.1:1 & 17.7 & 4.5 & $3.9: 1$ \\
\hline Lebanon & 42.3 & 30.6 & $1.4: 1$ & 11.8 & 5.6 & $2.1: 1$ \\
\hline Libyan Arab Jamahiriya & NA & NA & NA & 7.7 & 0.9 & $8.6: 1$ \\
\hline Gaza Strip & NA & NA & NA & 9.7 & 3.0 & $3.2: 1$ \\
\hline West Bank & NA & NA & NA & 27.6 & 8.7 & $3.2: 1$ \\
\hline Morocco & 28.5 & 0.1 & 285.0:1 & 4.3 & 2.1 & 2.0:1 \\
\hline Oman & 15.5 & 1.5 & 10.3:1 & 3.5 & 1.2 & 2.9:1 \\
\hline Qatar & 37.0 & 0.5 & 74.0:1 & 13.4 & 2.3 & $5.8: 1$ \\
\hline Somalia-Somaliland & NA & NA & NA & 4.9 & 4.5 & 1.1:1 \\
\hline Sudan & 23.5 & 1.5 & $15.7: 1$ & 10.2 & 2.1 & 4.9:1 \\
\hline Syrian Arab Republic & 44.3 & 5.7 & 7.8:1 & 19.1 & 5.9 & $3.2: 1$ \\
\hline Tunisia & 49.5 & 2.4 & $20.6: 1$ & 15.1 & 1.6 & $9.4: 1$ \\
\hline United Arab Emirates & 17.3 & 1.3 & 13.3:1 & 12.1 & 3.6 & $3.4: 1$ \\
\hline
\end{tabular}

${ }^{a}$ Source: [9].

GYTS = Global Youth Tobacco Surveys; NA = not available

of their plans for monitoring the $\mathrm{WHO}$ Framework Convention on Tobacco Control (WHO FCTC) [10]; all of these countries have ratified the $\mathrm{WHO}$ FCTC.

\section{Monitoring tobacco control efforts}

National Tobacco Control Action Plans are developed by governments to provide clear strategies for reducing and controlling tobacco use. A comprehensive tobacco control programme generally includes: public counter-marketing campaigns to reduce the effects of tobacco advertising, communitybased programmes to reduce tobacco use, cessation-assistance programmes, school-based programmes, enforcement of existing tobacco restrictions, monitoring and evaluation of the control programme and related policy efforts to support the programme, such as increased excise taxes, chronic disease programmes targeting tobacco-related health problems and environmental tobacco smoke restrictions. GYTS data can provide countries with valuable feedback to evaluate and improve $\mathrm{Na}$ tional Tobacco Control Action Plans and to develop plans where none exists.

\section{Monitoring the WHO FCTC}

The WHO FCTC, adopted by the 56th World Health Assembly in May 2003, is the world's first public health treaty on tobacco control. It provides the driving force and blueprint for the global response to the pandemic of tobacco-induced death and disease. The Convention embodies a coordinated, effective and urgent action plan to curb tobacco consumption, laying out costeffective tobacco control strategies on population-wide public policies, such as bans on direct and indirect tobacco advertising, tobacco taxes and price increases, smoke-free environments in all public places and workplaces, and large, clear, graphic health messages on tobacco packaging. In addition, the Convention encourages countries to address cross-border issues, such as illegal trade and duty-free sales [10].

The WHO FCTC and GYTS share the same goal: the development, implementation and evaluation of effective tobacco control programmes in all WHO Member States [11]. The GYTS can help measure many of the articles in the WHO FCTC. The WHO FCTC calls for countries to use consistent methods and procedures in their surveillance efforts. The GYTS was designed to provide consistent sampling procedures, core questionnaire items, training in field procedures and analysis of data across all survey sites.

The WHO FCTC also requires countries to be able to monitor the treaty's application. The GYTS helps each country establish applied research in public health and contributes to establishing continuous tobacco control surveillance and monitoring. The WHO FCTCalso contributes to strengthening the leadership capacity of the ministries of health and other state health bodies responsible for tobacco control, not only in terms of public health advocacy, but also in negotiations with other sectors with respect to tobacco control. The GYTS also enhances the role of the nongovernmental sector by supporting 
civil society participation in surveillance, monitoring, and policy and programme development.

\section{Conclusion}

Tobacco use represents the single greatest preventable cause of death worldwide. Every year nearly 5 million people die from tobacco-related illnesses, and this number is expected to more than double by 2030 [12]. The findings from this study offer 13
EMR countries and the Gaza Strip/ West Bank reliable baseline data that can be used to develop, implement and evaluate their comprehensive tobacco control programmes.

\section{Acknowledgement}

The authors appreciate the contribution of each of the following Country GYTS research coordinators: Ehab Makram (Egypt), Mohamed Mehrez (Egypt), Iman Al Jaghbeer (Jordan),
Samy Eissa Al-Nasser (Kuwait), Georges Saade (Lebanon), Ahmed Buni (Libyan Arab Jamahiriya), Moain El Kariri (Gaza Strip/West Bank), Abdelkhalek Moujarrade (Morocco), Salah Al Muzahmi (Oman), Hamda Qotba (Qatar), Ali Sheikh Omaer Kabil (Somalia), Ibrahim Ginawi (Sudan), Bassam Abu Al Zahab (Syrian Arab Republic), Radhouane Fakhfakh (Tunisia), Ayesha Al-Mutawa (United Arab Emirates). The high quality and reliability of the GYTS data are a tribute to their leadership and direction.

\section{References}

1. Jha P, Chaloupka FJ. Tobacco Control in Developing Countries. Oxford, Oxford University Press, 2000.

2. Warren CW et al. Global Youth Tobacco Surveillance - 20002007. Centers for Disease Control and Prevention, Surveillance Summaries, 2008. MMWR, 2008, 57(no. SS-1).

3. Pierce JP et al. Validation of susceptibility as a predictor of which adolescents take up smoking in the United States. Health psychology, 1996, 15(5):355-61.

4. Shah BV, Barnwell BG, Bieler GS. Software for the statistical analysis of correlated data (SUDAAN): User's Manual. Release 7.5. 1997 (software documentation). Research Triangle Park, NC, Research Triangle Institute, 1997.

5. Pierce $\mathrm{J}$ et al. Tobacco industry promotion of cigarettes and adolescent smoking. Journal of the American Medical Association, 1998, 279(7):505-11.

6. Hochberg A. Critics fume over marketing of "Camel No. 9". NPR, March 16, 2007 (http://www.npr.org/templates/story/ story.php?storyld=8909745, accessed 21 March 2009).
7. Tobacco industry targeting of women and girls. Washington DC, Campaign for Tobacco-Free Kids, 2007 (Fact sheet, May 7).

8. Waldron I et al. Gender differences in tobacco use in Africa, Asia, the Pacific and Latin America. Social science and medicine, 1988, 27:1269-75.

9. Mackay J, Eriksen M, Shafey O. The tobacco atlas, 2nd ed. Atlanta, American Cancer Society, 2006.

10. WHO Framework Convention on Tobacco Control. Geneva, World Health Organization, 2003.

11. Global Tobacco Surveillance System Collaborating Group. Global Tobacco Surveillance system (GTSS): purpose, production, and potential. Journal of school health, 2005, 75(1):1524.

12. Peto R, Lopez AD. Future worldwide health effects of current smoking patterns. In: Koop CE, Pearson CE, Schwarz MR, eds. Critical issues in global health. San Francisco, Jossey-Bass; 2001. 